\title{
Does chemoradiotherapy benefit elderly patients with esophageal squamous cell cancer? A propensity-score matched analysis on multicenter data (3JECROG R- 03A)
}

Mingqiu Chen ${ }^{1 \dagger}$, Xiaohong Liu ${ }^{2 \dagger}$, Chun Han ${ }^{3}$, Xin Wang ${ }^{4}$, Yidian Zhao ${ }^{5}$, Qingsong Pang ${ }^{6}$, Xinchen Sun ${ }^{7}$, Gaofeng Li $i^{8}$, Kaixian Zhang ${ }^{9}$, Ling Li ${ }^{9}$, Xueying Qiao ${ }^{3}$, Yu Lin ${ }^{1}$, Junqiang Chen ${ }^{1 *}$ (D) and Zefen Xiao ${ }^{4^{*}}$

\begin{abstract}
Background: The aim of the present study was to assess the efficacy of concurrent chemoradiotherapy (CRT) or radiotherapy alone (RT-alone) in elderly patients with esophageal squamous cell carcinoma (ESCC).

Methods: The clinical data of patients with ESCC treated with RT-alone or CRT were collected and retrospectively reviewed. The 1-, 3- and 5-year overall survival (OS) rates and the clinical characteristics correlated with survival were analyzed statistically. Propensity score matching (PSM) analyses were used to compensate for differences in baseline characteristics between the CRT and RT-alone groups to confirm the survival difference.

Results: A total of 729 patients fulfilling the inclusion criteria were reviewed. Diabetes, primary tumor volume (pTV), primary tumor location (pTLo), clinical T stage,(cT) clinical N stage (cN), clinical M stage (cM) and short-term response to RT were independent factors influencing OS $(P=0.002-0.044)$. The 5-year OS rate was 26.6, 26.0 and $30.1 \%$ in the whole cohort, RT-alone and CRT groups, respectively. The survival difference between RT alone and CRT was not significant before or following PSM. Compared with the corresponding subgroups treated with RT alone, CRT significantly benefited patients with diabetes $(P=0.003)$, $C T 4(P=0.030)$ and $\mathrm{CNO}(P=0.049)$, whereas no benefit was identified between CRT and RT alone in the other subgroups, including $C T 1-3, C N 1, C M$, PTLo, pTV, age and gender.
\end{abstract}

Conclusions: CRT with the current chemotherapy regimens may not improve the survival of elderly ESCC patients compared to RT-alone, except in patients with cT4 stage, cNO stage or diabetes. However, due to the limitation of the retrospective nature of the current study, further clinical trials are required for confirmation.

Keywords: Concurrent chemoradiotherapy, Elderly, Esophageal squamous cell carcinoma, Survival

\footnotetext{
* Correspondence: junqiangc@163.com; xiaozefen@sina.com

${ }^{\dagger}$ Mingqiu Chen and Xiaohong Liu contributed equally to this work.

'Department of Radiation Oncology, Fujian Cancer Hospital \& Fujian Medical University Cancer Hospital, No. 420, Fumalu Road, Jinan District, Fuzhou City, Fujian Province, People's Republic of China

${ }^{4}$ Department of Radiation Oncology, National Cancer Center/National Clinical

Research Center for Cancer/Cancer Hospital, Chinese Academy of Medical

Sciences and Peking Union Medical College, Beijing 100021, China

Full list of author information is available at the end of the article
}

(c) The Author(s). 2019 Open Access This article is distributed under the terms of the Creative Commons Attribution 4.0 International License (http://creativecommons.org/licenses/by/4.0/), which permits unrestricted use, distribution, and reproduction in any medium, provided you give appropriate credit to the original author(s) and the source, provide a link to the Creative Commons license, and indicate if changes were made. The Creative Commons Public Domain Dedication waiver (http://creativecommons.org/publicdomain/zero/1.0/) applies to the data made available in this article, unless otherwise stated. 


\section{Background}

Esophageal cancer (EC) is the seventh most common cancer, with an estimated 572,000 new cases and 509,000 deaths in 2018 [1]. EC is rare among young individuals and increases in incidence with age, peaking in the seventh and eighth decades of life [2]. With the increased age of the general population, the number of elderly patients with EC is expected to increase in the foreseeable future.

Esophagectomy is considered an effective treatment for EC. However, due to physiological limitations and high operative morbidity and mortality, elderly patients with EC are reluctant to undergo surgical procedures [3]. For patients with unresectable or medically inoperable EC, concurrent chemoradiotherapy (CRT) is considered an optimal alternative. Due to intolerance to the acute toxicities of standard CRT [4], most elderly patients require an altered treatment strategy. The efficacy of CRT in elderly patients with EC had not been established, due to conflicting and inconclusive results from previous studies [5-7].

In the current study, the clinical data of elderly patients with esophageal squamous cell cancer (ESCC) initially treated with radiotherapy alone (RT-alone) or CRT were collected retrospectively to explore the role of CRT in elderly patients with ESCC.

\section{Methods}

\section{Patient selection criteria}

This retrospective study was approved by Fujian Cancer Hospital \& Fujian Medical University Cancer Hospital (No.SQ2019-037-01) and National Cancer Center/National Clinical Research Center for Cancer/Cancer Hospital (NCC2016-06) Institutional Review Board. All patients provided written informed consent prior to treatment, and all information was anonymized prior to analysis.

The eligibility and exclusion criteria for the present retrospective study were similar to those of our previous study [8], except patient age. In brief: histologically proven ESCC; $>70$ years old and life expectancy $\geq 3$ months; pretreatment assessment available to define the clinical stage and to assess the suitability for RT-alone or CRT; Eastern Cooperative Oncology Group scoring (ECOG) $\leq 3$; clinical stage of $\mathrm{T}_{\text {any }} \mathrm{N}_{\text {any }} \mathrm{M}_{0}$ or $\mathrm{M}_{1}$ only with supraclavicular lymph node metastasis (SLNM); no neoor adjuvant chemotherapy; no post-RT salvage surgery performed; and sufficient follow-up data available for survival assessment.

The clinical TNM stage was determined according to the 7th American Joint Committee on Cancer (AJCC) TNM staging system, based on computed tomography (CT) scanning data of T, $\mathrm{N}$ and $\mathrm{M}$ stage.

\section{Radiotherapy and concurrent chemoradiotherapy}

All enrolled patients were administered radical CRT or RTalone. The RT technology consisted of three-dimensional conformal radiation therapy (3D-CRT) or intensitymodulated radiation therapy (IMRT). The concurrent chemotherapy (CC) time intervals and dose intensities were reported in our previous study [9].

The targets, including gross tumor volume, clinical target volume and organs at risk of radiotherapy, the target dose and the dose limitations of organs at risk were defined and adjusted as described in our previous study [9].

\section{Surveillance and statistical analysis}

The follow-up schedule for patients was as previously reported [9]. In brief, patients were assessed every 3 months for the first 2 years after RT, every 6 months for the next 3 years, and then once annually. All patient outcomes were evaluated in March 2018. The primary endpoint of the current study was overall survival (OS), which was calculated from the date of RT completion to the date of mortality or final follow-up.

Data were analyzed using SPSS, version 24.0 (IBM Corp., Armonk, NY, USA). Survival curves were generated using the Kaplan-Meier estimator method and compared using the log-rank test. Univariate and multivariate analyses, including age, gender, frequently preexisting chronic comorbidities, treatment modality, primary tumor length (pTL), primary tumor location (pTLo), primary tumor volume (pTV), cT stage, cN stage, cM stage, cTNM stage, radiation dose of GTV, radiotherapy technology, cycles and regimens of $\mathrm{CC}$, were performed using the Cox proportional hazards model. Confidence intervals (CI) represented 95\% lower and upper bounds. $P \leq 0.05$ was considered to indicate a statistically significant difference.

According medical history records, the following four diseases were considered the most frequently preexisting chronic comorbidities: hypertension, cardiovascular disease, pulmonary disease and diabetes.

Propensity score matching (PSM) analyses were used to compensate for differences in baseline characteristics between the CRT and RT-alone groups to confirm the survival difference. First, the Cox hazard model was utilized to determine all available patients and variables correlated with OS by univariable analyses. Next, all the unbalanced variables that were statistically significantly correlated with OS were adjusted by PSM with a match tolerance value at 0.1 [10]. Pearson's $X^{2}$ test or an independent samples t-test was subsequently performed to compare the differences between the CRT and RT-alone groups after matching.

\section{Results}

\section{Patient characteristics}

Between September 1, 2004 and December 31, 2015, a total of 961 patients with ESCC treated with RT were reviewed. A total of 729 patients fulfilled the inclusion criteria, of whom 133 (18.2\%) patients were administered 
with CRT and 596 (81.8\%) patients were treated with RT-alone. The clinical characteristics of patients are summarized in Table 1.

A median number of 2 (range, 1-4) cycles of CC were administered to CRT patients. The regimens of CC included: single-agent fluoropyrimidine (5-fluorouracil, tegafur, carmofur or capecitabine, $n=16)$ or cisplatin $(n=$ $24)$ or taxane $(n=12)$; dual-agent platinum compound (cisplatin, lobaplatin, nidaplatinum or oxaliplatin) plus fluoropyrimidine (5-fluorouracil or capecitabine; PF) $(n=$ $42)$ or a platinum compound plus taxane (paclitaxel or docetaxel; TP) $(n=4)$; and dual- to single-agent (initially with dual-agent and then with single-agent, $n=35$ ).

\section{Treatment failure and survival analysis in the entire} cohort

At the last follow-up in March, 2018, 201 patients remained alive and 528 patients had died, of whom 266 (50.3\%) patients had succumbed to primary or locoregional tumor relapse, $132(25.0 \%)$ patients to distant metastasis, and 24 (4.6\%) to both locoregional and distant metastasis; 20 (3.8\%) had died from treatment complications (18 patients in RT-alone and two patients in CRT, respectively), 50 (9.5\%) patients had died of non-tumor disease, and 36 (6.8\%) patients had succumbed to unknown causes.

The median follow-up time in the entire cohort and in the surviving patients was $21.7(1.6-141.2)$ and 50.8 (3.3141.2) months, respectively. The $1-, 3$ - and 5 -year OS rate in the entire cohort, CRT and RT-alone groups are presented in Table 2. The survival difference between CRT and RT-alone was not significant $(P=0.854$; Fig. 1$)$.

Univariate and multivariate analyses in the entire cohort indicated that diabetes $(P=0.044)$, pTV $(P=0.026)$, pTLo $(P=0.004)$, cT stage $(P=0.028), \mathrm{cN}$ stage $(P=$ $0.023)$, cM stage $(P=0.002)$ and short-term response to RT $(P=0.003)$ were independent factors influencing OS (Table 3).

\section{Survival benefit of CRT in various subgroups following PSM}

To balance bias between CRT and RT-alone due to the retrospective nature of this study, PSM, based on the clinical baseline characteristics including gender, age, ECOG, pTL, pTV, pTLo, cT, cN, cM and four chronic comorbidities, was conducted. Following PSM, a total of 234 events were identified in both the matched CRT and RT-alone groups, with 117 patients in each group.

Following PSM, no significant differences in clinical characteristics were identified between the two matched groups, with the exception of gender (Table 1), which did not influence patient survival in the subsequent univariate and multivariate analyses. Univariate and multivariate analyses in the PSM patients demonstrated that only diabetes $(P=0.028)$, cT $(P=0.028)$, cN $(P=0.001)$ and $\mathrm{cM}(P=0.001)$ were independent prognostic factors, while pTV, pTLo and short-term response to the RT did not independently affect patient survival.

Following PSM, the OS differences were still not significantly different between CRT and RT-alone (Fig. 2a). To identify patients who may benefit from CRT, exploratory analyses were conducted among various patient subgroups following PSM. The results indicated that compared with the corresponding subgroups treated with RT-alone, CRT significantly benefited patients with diabetes $(P=0.003)$, cT4 $(P=0.030)$ and cN0 $(P=0.049)$ (Fig. 2b, c, d). By contrast, no benefit was identified between CRT and RTalone in the other subgroups, including cT1-3, cN1, cM stage, pTLo, pTV, age and gender.

\section{Discussion}

Due to physiological limitations and tolerance to the toxicity of aggressive treatment, elderly patients with ESCC are usually given palliative care to prevent deterioration of the general condition of patients. However, cumulative studies have proven that elderly patients with EC achieve long-term survival from curative treatment, such as radical esophagectomy or definitive RT or CRT [11-13]. Alberto et al reported that short- and long-term outcomes after esophagectomy for EC in patients older than 70 years are comparable with those of their younger counterparts [14]. $\mathrm{Xu}$ et al reported that, compared to young patients with similar prognostic status, the elderly population exhibits similar long-term survival following definitive CRT [15]. In the current study, which enrolled patients aged over 70 who were treated with RT or CRT, the 5-year OS rate of the whole cohort was similar to that of our previous studies, which enrolled patients aged under 70 (with an OS rate of $27.2 \%$ at 5 years) [8]. The results confirmed that old age should not be a contraindication for curative treatment in patients with EC.

Although advanced age is not a contraindication for aggressive treatment, data on whether CRT is superior to RT alone for patients with unresectable or medically inoperable ESCC are scarce, and the efficacy of definitive CRT has not been established [16]. Zhao et al reported that CRT with platinum and 5-FU is well-tolerated and more effective than RT alone for elderly patients older than 75 years with locally advanced ESCC [17]. In the current study, the survival rates between the CRT and RT-alone groups were not significantly different, whether in pre- or post-PSM. The impact of treatment complications on survival is often a common explanation for this discrepancy. However, the treatmentrelated mortality rate between RT-alone and CRT was not found to be significantly different in the current study. Therefore, for elderly patients with ESCC, combined treatment of RT with a contemporary regimen of chemotherapy should be conducted cautiously [18]. 
Table 1 Clinical characteristics of pre- and post-matched patients

\begin{tabular}{|c|c|c|c|c|c|c|c|c|}
\hline \multirow[t]{2}{*}{ Characteristics } & \multicolumn{4}{|l|}{ Pre-PSM } & \multicolumn{4}{|l|}{ Post-PSM } \\
\hline & $\overline{\text { CRT }}$ & RT-alone & $x^{2}$ & $P$ & $\overline{\text { CRT }}$ & RT-alone & $x^{2}$ & $P$ \\
\hline Gender (n) & & & 0.141 & 0.708 & & & 4.607 & 0.042 \\
\hline Male & 84 & 366 & & & 76 & 91 & & \\
\hline Female & 49 & 230 & & & 41 & 26 & & \\
\hline Mean age (year) & $73.3 \pm 3.58$ & $76.2 \pm 4.39$ & & $<0.001$ & $73.8 \pm 3.7$ & $73.9 \pm 3.8$ & & 0.875 \\
\hline ECOG (n) & & & 29.776 & $<0.001$ & & & 6.838 & 0.078 \\
\hline 0 & 15 & 208 & & & 15 & 23 & & \\
\hline 1 & 46 & 156 & & & 42 & 38 & & \\
\hline 2 & 66 & 203 & & & 57 & 46 & & \\
\hline 3 & 6 & 29 & & & 3 & 10 & & \\
\hline \multicolumn{9}{|l|}{ Preexisting chronic comorbidities (n) } \\
\hline \multicolumn{9}{|l|}{ Hypertension } \\
\hline yes & 33 & 207 & 4.845 & 0.032 & 32 & 28 & 0.359 & 0.654 \\
\hline no & 100 & 389 & & & 85 & 89 & & \\
\hline \multicolumn{9}{|l|}{ Cardiovascular disease } \\
\hline yes & 16 & 78 & 0.108 & 0.886 & 14 & 22 & 2.101 & 0.204 \\
\hline no & 117 & 518 & & & 103 & 95 & & \\
\hline \multicolumn{9}{|l|}{ Pulmonary disease } \\
\hline yes & 14 & 57 & 0.115 & 0.747 & 13 & 20 & 1.729 & 0.26 \\
\hline no & 119 & 539 & & & 104 & 97 & & \\
\hline \multicolumn{9}{|l|}{ Diabetes } \\
\hline yes & 12 & 69 & 0.718 & 0.449 & 11 & 13 & 0.186 & 0.83 \\
\hline no & 121 & 527 & & & 106 & 104 & & \\
\hline Tumor location (n) & & & 10.204 & 0.037 & & & 4.728 & 0.316 \\
\hline Cervical & 10 & 19 & & & 9 & 4 & & \\
\hline Upper & 40 & 137 & & & 30 & 39 & & \\
\hline Middle & 51 & 288 & & & 46 & 47 & & \\
\hline Lower & 32 & 150 & & & 32 & 26 & & \\
\hline EGJ & 0 & 2 & & & 0 & 1 & & \\
\hline Mean primary tumor length $(\mathrm{cm})$ & $5.50 \pm 2.30$ & $5.38 \pm 2.27$ & & 0.564 & $5.5 \pm 2.1$ & $5.7 \pm 2.4$ & & 0.426 \\
\hline Mean primary tumor volume $(\mathrm{cm} 3)$ & $50.82 \pm 34.6$ & $44.91 \pm 33.14$ & & 0.255 & $50.2 \pm 35.4$ & $52.8 \pm 32.4$ & & 0.56 \\
\hline Clinical T stage $(n)$ & & & 8.959 & 0.03 & & & 3.411 & 0.333 \\
\hline $\mathrm{T} 1$ & 0 & 10 & & & 0 & 3 & & \\
\hline $\mathrm{T} 2$ & 14 & 113 & & & 13 & 10 & & \\
\hline $\mathrm{T} 3$ & 56 & 245 & & & 53 & 52 & & \\
\hline $\mathrm{T} 4$ & 63 & 228 & & & 51 & 52 & & \\
\hline Clinical N stage $(n)$ & & & 0.14 & 0.769 & & & 0.018 & 1 \\
\hline No & 51 & 239 & & & 46 & 45 & & \\
\hline N1 & 82 & 357 & & & 71 & 72 & & \\
\hline Clinical M stage (n) & & & 13.287 & 0.001 & & & 0.186 & 0.83 \\
\hline Mo & 114 & 564 & & & 106 & 104 & & \\
\hline M1 & 19 & 32 & & & 11 & 13 & & \\
\hline Primary T GTV Dose (cGy) & $6120 \pm 253$ & $6067 \pm 334$ & & 0.084 & $6105 \pm 249$ & $6052 \pm 389$ & & 0.212 \\
\hline
\end{tabular}

Cardiovascular disease: coronary artery disease [CAD] and atrial fibrillation [AF]

Pulmonary disease: chronic obstructive pulmonary disease [COPD] and asthma

EGJ Esophagogastric junction

PSM Propensity score matching 
Table 2 Overall survival rate in the various subgroups and failure pattern in the entire cohort

\begin{tabular}{|c|c|c|c|c|}
\hline Overall survival rate (\%) & 1- year & 3- year & 5- year & $P$ \\
\hline Treatment & & & & 0.854 \\
\hline RT-alone & 71.9 & 36.6 & 26 & \\
\hline CRT & 72.4 & 38.5 & 30.1 & \\
\hline Whole & 72 & 36.9 & 26.6 & \\
\hline Diabetes & & & & 0.035 \\
\hline yes & 66.5 & 24.1 & 16 & \\
\hline no & 72.6 & 38.4 & 27.8 & \\
\hline \multicolumn{5}{|l|}{ pTLo } \\
\hline upper & 77.2 & 46.9 & 33.5 & 0.001 \\
\hline middle & 69.5 & 32.6 & 21.5 & 0.006 \\
\hline lower & 69.5 & 33.8 & 28.2 & 0.829 \\
\hline $\mathrm{pTV}\left(\mathrm{cm}^{3}\right)$ & & & & $<0.001$ \\
\hline$\leq 32$ & 79.8 & 46.7 & 36.1 & \\
\hline$>32$ & 66.8 & 31 & 21.2 & \\
\hline \multicolumn{5}{|l|}{ cT } \\
\hline 1 & 90 & 80 & 70 & 0.21 \\
\hline 2 & 75.6 & 40 & 33.7 & 0.16 \\
\hline 3 & 75.9 & 36.7 & 28.5 & 0.1 \\
\hline 4 & 64.9 & 33.8 & 20.4 & \\
\hline $\mathrm{cN}$ & & & & 0.001 \\
\hline 0 & 77.2 & 46.8 & 32.7 & \\
\hline 1 & 68.1 & 30.4 & 22.5 & \\
\hline CM & & & & $<0.001$ \\
\hline 0 & 72.8 & 38.2 & 27.4 & \\
\hline 1 & 56.6 & 16.9 & 16.9 & \\
\hline Failure Pattern (n) & Total & RT & CRT & $P$ \\
\hline locoregional & 266 & 226 & 40 & 0.209 \\
\hline distant & 132 & 103 & 29 & \\
\hline locoregional and distant & 24 & 20 & 4 & \\
\hline treatment complication & 20 & 18 & 2 & \\
\hline non-tumor disease & 50 & 41 & 9 & \\
\hline unknown causes & 36 & 34 & 2 & \\
\hline
\end{tabular}

pTLo Primary tumor location

$p T V$ Primary tumor volume

Other potential reasons for the inconsistency are the inadequate intensity of chemotherapy and unified chemotherapy regimens in the current study. However, to date, the appropriate doses and schedules of chemotherapy for these patients are yet to be determined [19]. Several studies had proven that dual-agent therapy achieved superior survival than single-agent CRT for elderly patients with ESCC [20, 21]. Zhao et al demonstrated that CRT with a single agent in elderly patients had a similar survival benefit compared to CRT with a dual agent, accompanied by less toxicity [22]. Similar to
Zhao et al, in the current study, the survival of patients treated with $\mathrm{CRT}$ with various $\mathrm{CC}$ regimens or CC cycles did not alter significantly. The aforementioned results indicate that the efficacy of CC in patients treated with RT is debatable, and novel drug treatment options with lower toxicity and higher efficacy must be developed for elderly patients with ESCC [23, 24].

Despite the controversies, some studies have argued that CRT should be considered for a certain subgroup rather than for all elderly ESCC patients. Zhang et al reported a single-center retrospective study demonstrating that, compared with RT-alone, only elderly ESCC patients aged 65-72, and not patients older than 72 years, benefited from CRT in terms of survival [5]. To identify which subgroup of patients may benefit from CRT, exploratory subgroup analyses basing on the potential factors influencing prognosis were performed in the present study. The results demonstrated that, compared with RT alone, CRT did not confer a survival benefit to elderly patients in the various subgroups, except cT4, cN0 or diabetic patients.

The T category of the current AJCC staging system is based on anatomical information related to primary tumor invasion of the esophageal wall. Although CRT was considered an optimal treatment for unresectable EC, its feasibility and effectiveness for T4 tumors, which are defined by invasion of the adjacent structures and are not indicated for surgery, is still unclear, and a high incidence of esophageal perforation has been reported after standard CRT for T4 tumors [25]. Previous studies have reported the use of a low-dose concurrent chemotherapy regimen to obtain the maximal radiosensitizing effect, which may improve patient survival without the rapid depopulation of massive T4 tumors and perforation caused by full-dose chemotherapy [26-28]. The current study, similar to Nishimura et al [28], demonstrated that CRT compared to RT alone achieved superior survival in CT4 patients. The results suggested that, even in elderly patients, patients with more advanced disease should be administered more aggressive treatments to improve their survival.

Lymph node metastasis (LNM) is a poor prognosis factor in patients with ESCC and an indicator that more intensive treatment may be required $[29,30]$. Numerous studies in non-elderly patients have found that for patients with LNM, CRT can achieve a greater survival benefit than RT-alone [31]. However, the efficacy of CC in elderly ESCC patients with LNM treated with RT had not been confirmed. The current study took the lead in discussing this topic. Unfortunately, contrary to the nonelderly patients, the current study found that whether in the entire cohort or in the PSM patients, compared with RT-alone, CRT benefited survival only in N0 patients, and not in N1 patients who were hypothesized to benefit 


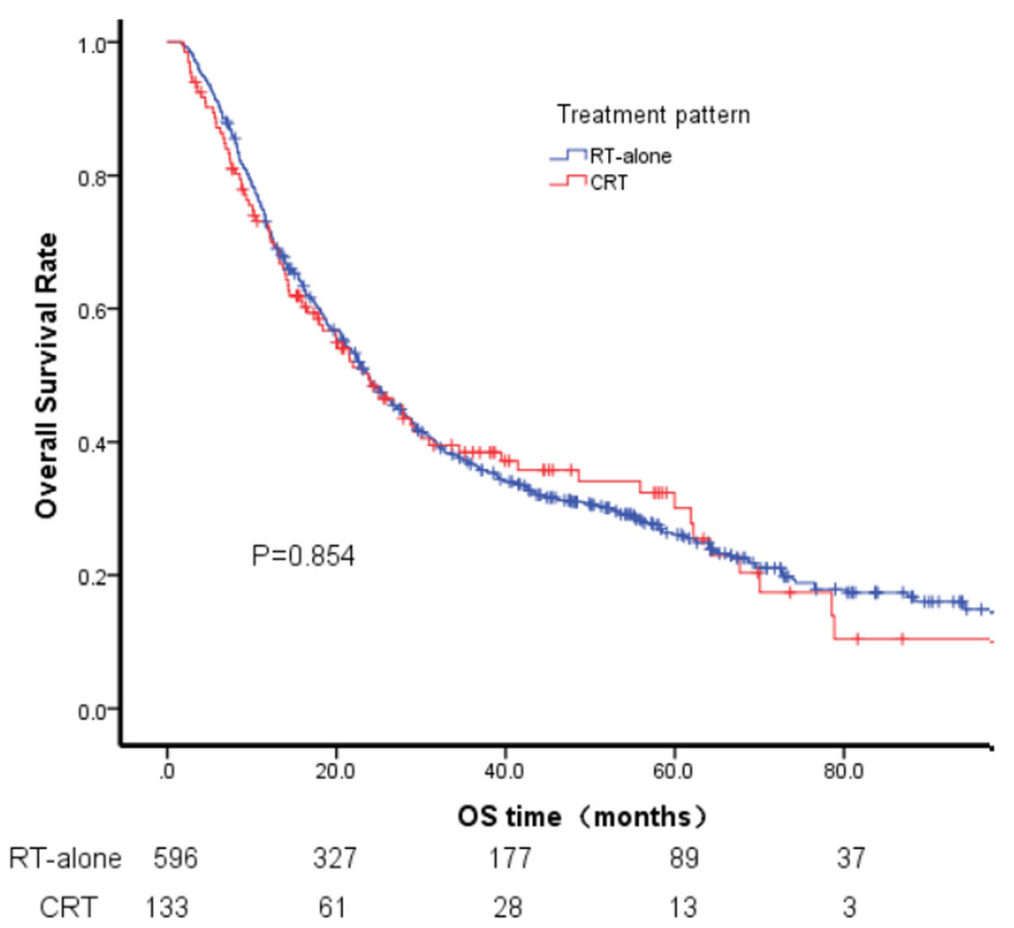

Fig. 1 Survival between CRT and RT-alone across the whole cohort

Table 3 Prognostic factors by univariate and multivariate analyses

\begin{tabular}{|c|c|c|c|c|c|c|}
\hline & \multicolumn{4}{|l|}{ Pre-PSM } & \multirow{2}{*}{\multicolumn{2}{|c|}{$\begin{array}{l}\text { Post-PSM } \\
\text { multivariate analyses }\end{array}$}} \\
\hline & \multicolumn{2}{|c|}{ univariate analyses } & \multicolumn{2}{|c|}{ multivariate analyses } & & \\
\hline & $P$ & $\mathrm{HR}(95 \% \mathrm{Cl})$ & $P$ & $\mathrm{HR}(95 \% \mathrm{Cl})$ & $P$ & $\mathrm{HR}(95 \% \mathrm{Cl})$ \\
\hline Gender & 0.184 & $0.886(0.742-1.059)$ & & & & \\
\hline Age & 0.418 & $1.008(0.989-1.028)$ & & & & \\
\hline ECOG & 0.796 & $1.013(0.921-1.113)$ & & & & \\
\hline Hypertension & 0.999 & $1.000(0.834-1.199)$ & & & & \\
\hline Cardiovascular disease & 0.806 & $1.032(0.805-1.323)$ & & & & \\
\hline Pulmonary disease & 0.795 & $1.038(0.782-1.379)$ & & & & \\
\hline Diabetes & 0.036 & $1.326(1.019-1.726)$ & 0.044 & $1.314(1.007-1.714)$ & 0.028 & $1.643(1.056-2.555)$ \\
\hline Tumor location & 0.006 & $1.160(1.044-1.289)$ & 0.004 & $1.174(1.052-1.311)$ & & \\
\hline Primary tumor length & 0.001 & $1.063(1.024-1.102)$ & & & & \\
\hline Primary tumor volume & $<0.001$ & $1.063(1.024-1.102)$ & 0.026 & $1.003(1.000-1.006)$ & & \\
\hline Clinical T stage & 0.001 & $1.207(1.079-1.351)$ & 0.028 & $1.146(1.015-1.295)$ & 0.028 & $1.270(1.026-1.571)$ \\
\hline Clinical N stage & 0.001 & $1.351(1.131-1.613)$ & 0.023 & $1.237(1.030-1.485)$ & 0.001 & $1.673(1.223-2.287)$ \\
\hline Clinical M stage & $<0.001$ & $1.825(1.308-2.545)$ & 0.002 & 1.703 (1.209-2.399) & 0.001 & $1.965(1.295-2.983)$ \\
\hline GTV dose & 1.398 & $1.000(1.000-1.000)$ & & & & \\
\hline Technique & 0.676 & $0.964(0.811-1.146)$ & & & & \\
\hline Treatment pattern & 0.854 & $1.022(0.811-1.288)$ & & & & \\
\hline Short-term response to RT & 0.001 & $1.263(1.095-1.457)$ & 0.003 & $1.243(1.076-1.435)$ & & \\
\hline
\end{tabular}




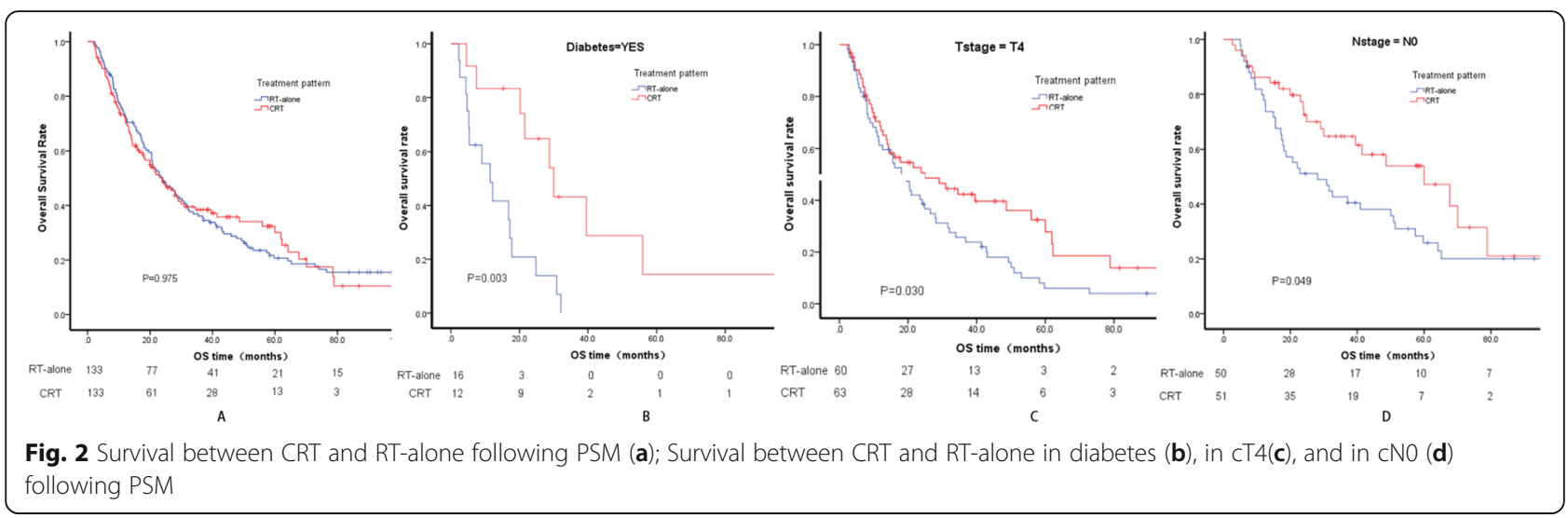

from CC. The inaccurate division of the $\mathrm{cN}$ stage into $\mathrm{N} 0$ and N1 may have explained the results of the current study. The accurate determination of $\mathrm{cN}$ stage based on a CT scan image is crucial for the re-evaluation of the role of CRT in elderly patients with ESCC with LNM.

SLNM is still considered a distant metastatic disease even in the newest 8th edition of the AJCC TNM staging system [32], and palliative treatment is recommended by the NCCN guidelines. Recently, several studies have argued that SLNM does not constitute an important independent prognostic factor for patients treated with CRT $[33,34]$. Our previous data demonstrate that the OS of patients with $\operatorname{SLNM}(+)$ is superior to those with cN3 $\operatorname{SLNM}(-)$, and is similar to those with cN1 SLNM(-) or cN2 SLNM(-), but inferior to cN0 SLNM(-), confirming that SLNM should be treated with curative intent as a regional, rather than a distant, disease in patients with ESCC when treated with CRT [35]. However, in the current study, CRT failed to demonstrate a survival advantage in patients with SLNM compared to RT-alone whether in pre- or post-PSM patients. The enrolled sample of SLNM patients was too small in the current study, which may have been the reason for the lack of statistical differences.

Chronic comorbidities are thought to affect cancer patient outcomes [36-38] and impact treatment decisions. He et al reported that certain comorbidities (hypothyroidism/ levothyroxine) affect EC-specific survival in EC patients treated with CRT [39]. Barone et al reported that patients diagnosed with cancer who have preexisting diabetes are at increased risk for long-term, all-cause mortality compared with those without diabetes [37]. It is generally recognized that elderly patients are more frequently affected by different chronic comorbidities. However, the influence of chronic comorbidities on the survival of patients with ESCC treated with RT or CRT had not been reported. Similar to Barone et al [37], in the current study, among the four common chronic comorbidities, diabetes was the only one identified to be an negative factor affecting patient prognosis, whether in the entire cohort or the PSM patients. Further subgroup analysis found that compared to RT-alone, CRT improved patient survival significantly in diabetic patients, but not in non-diabetic patients. Certainly, despite the survival benefits, the greater risk posed by more aggressive treatment in elderly patients with chronic comorbidities must be kept in mind in clinical practice [38].

\section{Conclusions}

Our results demonstrated that CRT with the current chemotherapy regimens may not improve the survival of elderly ESCC compared to RT-alone, except in patients with $\mathrm{cT} 4$ or $\mathrm{cNO}$ or diabetes. However, the retrospective nature of the current study, for example the limited records of treatment-related toxicities, the imbalances between the patient characteristics, the diverse chemotherapy regimens, the suboptimal assessment of staging by $\mathrm{CT}$ scanning and the cancer-specific comprehensive geriatric assessment tool [40] make it difficult for us to extend our investigation to confirm the results. Thus, further clinical trials are required to evaluate the efficacy of CRT in elderly ESCC patients.

\section{Supplementary information}

Supplementary information accompanies this paper at https://doi.org/10. 1186/s12885-019-6461-z.

Additional file 1: Data of 729 elderly patients with esophageal squamous cell cancer.

\section{Abbreviations \\ 3D-CRT: Three-dimensional conformal radiation therapy; AJCC: American Joint Committee on Cancer; CC: Concurrent chemotherapy; Cl: Confidence intervals; CM: Clinical M stage; CN: Clinical N stage; CRT: Concurrent chemoradiotherapy; CT: Clinical T stage; CT: Computed tomography; EC: Esophageal cancer; ECOG: Eastern Cooperative Oncology Group scoring; ESCC: Esophageal squamous cell carcinoma; GTV: Gross tumor volume; IMRT: Intensity-modulated radiation therapy; LNM: Lymph node metastasis; OS: Overall survival; PSM: Propensity score matching; pTL: Primary tumor length; pTLo: Primary tumor location; pTV: Primary tumor volume; RT- alone: Radiotherapy alone; SLNM: Supraclavicular lymph node metastasis}

Acknowledgments

The authors thank all patients who participated in the present study. 


\section{Authors' contributions}

$M C$ and $J C$ obtained funding for the study and conceptualized and designed the study. XL, CH, XW, YZ, QP, XS, GL, KZ, LL, XQ, LY, JC and ZX collected the data. $M C$ and $X L$ screened, extracted and conducted data analysis. MC and $\mathrm{XL}$ drafted and revised the article. All authors have read and approved the final article. All authors listed have made a substantial, direct and intellectual contribution to the work, and approved it for publication.

\section{Funding}

This study was supported in part by grants from the Fujian Provincial Health \& Family Planning Commission (project no. 2016-ZQN-32), the Fujian Provincial Department of Science \& Technology (project no. 2018 J01306), the Fujian Provincial Department of Science \& Technology (project no. 2017Y9079), the Fujian Provincial Platform for Medical Laboratory Research, and Key Laboratory for Tumor Individualized Active Immunity (project no. FYKFKT2017015). The funding body had no role in the design of the study and collection, analysis and interpretation of data and in writing the manuscript.

\section{Availability of data and materials}

Data were applicable to this article in Additional file 1.

\section{Ethics approval and consent to participate}

This retrospective study was approved by Fujian Province Cancer Hospital Institutional Review Board (no. K201427). All patients provided written informed consent prior to treatment, and all information was anonymized prior to analysis.

\section{Consent for publication}

Not applicable.

\section{Competing interests}

The authors declare that they have no competing interests.

\section{Author details}

'Department of Radiation Oncology, Fujian Cancer Hospital \& Fujian Medical University Cancer Hospital, No. 420, Fumalu Road, Jinan District, Fuzhou City, Fujian Province, People's Republic of China. ${ }^{2}$ The Graduate School, Fujian Medical University, Fuzhou 350122, Fujian, China. ${ }^{3}$ Department of Radiation Oncology, the Fourth Hospital of Hebei Medical University, Shijiazhuang 050011, China. ${ }^{4}$ Department of Radiation Oncology, National Cancer Center/ National Clinical Research Center for Cancer/Cancer Hospital, Chinese Academy of Medical Sciences and Peking Union Medical College, Beijing 100021, China. ${ }^{5}$ Department 4th of Radiation Oncology, Anyang Cancer Hospital, Anyang 455000, China. ${ }^{6}$ Department of Radiation Oncology, Tianjin Medical University Cancer Institute and Hospital/National Clinical Research Center for Cancer, Tianjin 300060, China. 'Department of Radiation Oncology, the First Affiliated Hospital of Nanjing Medical University, Nanjing 210029, China. ${ }^{8}$ Department of Radiation Oncology, Beijing Hospital, National Center of Gerontology, Beijing 100730, China. ${ }^{9}$ Department of Oncology, Tengzhou Central People's Hospital, Tengzhou 277599, China.

Received: 12 June 2019 Accepted: 12 December 2019

\section{Published online: 15 January 2020}

\section{References}

1. Bray F, Ferlay J, Soerjomataram I, Siegel RL, Torre LA, Jemal A. Global Cancer Statistics 2018: GLOBOCAN Estimates of Incidence and Mortality Worldwide for 36 Cancers in 185 Countries. CA Cancer J Clin. 2018;68(6):394-424.

2. Rustgi AK, El-Serag HB. Esophageal carcinoma. N Engl J Med. 2014;371(26):2499-509.

3. Steyerberg EW, Neville B, Weeks JC, Earle CC. Referral patterns, treatment choices, and outcomes in locoregional esophageal cancer: a populationbased analysis of elderly patients. J Clin Oncol. 2007;25(17):2389-96.

4. Hamamoto Y, Akutsu Y, Nagashima F, Hironaka S, Ito Y, Kato K, Hara H, Tsubosa Y, Nakagawa S, Daiko H, et al. Multicenter questionnaire survey on patterns of care for elderly patients with esophageal squamous cell carcinoma by the Japan esophageal oncology group. Jpn J Clin Oncol. 2016;46(2):111-5.

5. Zhang P, Xi M, Zhao L, Shen JX, Li QQ, He LR, Liu SL, Liu MZ. Is there a benefit in receiving concurrent chemoradiotherapy for elderly patients with inoperable thoracic esophageal squamous cell carcinoma? PLoS One. 2014; 9(8):e105270.
6. Hagiwara K, Kochi M, Fujii M, Song K, Tamegai H, Watanabe M, Takayama Y, Suda H, Teshima Y, Takayama T. Radiochemotherapy for esophageal squamous cell carcinoma in elderly patients. Hepato-gastroenterology. 2014;61(134):1617-22.

7. Semrau R, Herzog SL, Vallbohmer D, Kocher M, Holscher A, Muller RP. Radiotherapy in elderly patients with inoperable esophageal cancer. Is there a benefit? Strahlenther Onkol. 2012;188(3):226-32.

8. Chen M, Shen M, Lin Y, Liu P, Liu X, Li X, Li A, Yang R, Ni W, Zhou X, et al. Adjuvant chemotherapy does not benefit patients with esophageal squamous cell carcinoma treated with definitive chemoradiotherapy. Radiat Oncol. 2018;13(1):1-8.

9. Chen MQ, Lin QL, Chen YG, Guo JH, Xu BH, Tian Y. Neoadjuvant chemotherapy may not benefit esophageal squamous cell carcinoma patients treated with definitive chemoradiotherapy. J Chin Med Assoc. 2017;80(10):636-43.

10. Austin PC. Balance diagnostics for comparing the distribution of baseline covariates between treatment groups in propensity-score matched samples. Stat Med. 2009;28(25):3083-107.

11. Xu H-Y, Du Z-D, Zhou LIN, Yu MIN, Ding Z-Y, Lu YOU. Safety and efficacy of radiation and chemoradiation in patients over 70 years old with inoperable esophageal squamous cell carcinoma. Oncol Lett. 2014;7(1):260-6.

12. Vlacich G, Samson PP, Perkins SM, Roach MC, Parikh PJ, Bradley JD, Lockhart AC, Puri V, Meyers BF, Kozower B, et al. Treatment utilization and outcomes in elderly patients with locally advanced esophageal carcinoma: a review of the National Cancer Database. Cancer Med. 2017;6(12):2886-96.

13. Voncken FEM, van der Kaaij RT, Sikorska K, van Werkhoven E, van Dieren JM, Grootscholten C, Snaebjornsson P, van Sandick JW, Aleman BMP. Advanced age is not a contraindication for treatment with curative intent in esophageal Cancer. Am J Clin Oncol. 2018;41(9):919-26.

14. Ruol A, Portale G, Zaninotto G, Cagol M, Cavallin F, Castoro C, Sileni VC, Alfieri R, Rampado S, Ancona E. Results of esophagectomy for esophageal cancer in elderly patients: age has little influence on outcome and survival. J Thorac Cardiovasc Surg. 2007;133(5):1186-92.

15. Xu C, Xi M, Moreno A, Shiraishi Y, Hobbs BP, Huang M, Komaki R, Lin SH. Definitive Chemoradiation therapy for esophageal Cancer in the elderly: clinical outcomes for patients exceeding 80 years old. Int J Radiat Oncol Biol Phys. 2017;98(4):811-9.

16. Servagi-Vernat $\mathrm{S}$, Crehange G, Bonnetain F, Mertens C, Brain E, Bosset JF Chemoradiation in elderly esophageal cancer patients: rationale and design of a phase 1/II multicenter study (OSAGE). BMC Cancer. 2017;17(1):483.

17. Zhao Q, Hu G, Xiao W, Chen Y, Shen M, Tang Q, Ning X. Comparison of definitive chemoradiotherapy and radiotherapy alone in patients older than 75 years with locally advanced esophageal carcinoma: a retrospective cohort study. Medicine. 2017;96(35):e7920.

18. Pignon T, Gregor A, Schaake Koning C, Roussel A, Van Glabbeke M, Scalliet P. Age has no impact on acute and late toxicity of curative thoracic radiotherapy. Radiother Oncol. 1998;46(3):239-48.

19. Uno T, Isobe K, Kawakami H, Ueno N, Kobayashi H, Shimada H, Mastubara H, Okazumi S, Nabeya Y, Shiratori T, et al. Efficacy and toxicities of concurrent chemoradiation for elderly patients with esophageal cancer. Anticancer Res. 2004;24(4):2483-6.

20. Li X, Zhao L-J, Liu N-B, Zhang W-C, Pang Q-S, Wang P, Yuan Z-Y. Feasibility and efficacy of concurrent Chemoradiotherapy in elderly patients with esophageal squamous cell carcinoma: a respective study of 116 cases from a single institution. Asian Pac J Cancer Prev. 2015;16(4):1463-9.

21. Li J, Gong Y, Diao P, Huang Q, Wen Y, Lin B, Cai H, Tian H, He B, Ji L, et al. Comparison of the clinical efficacy between single-agent and dual-agent concurrent chemoradiotherapy in the treatment of unresectable esophageal squamous cell carcinoma: a multicenter retrospective analysis. Radiat Oncol. 2018;13(1):12.

22. Zhao L, Zhou Y, Pan H, Yin Y, Chai G, Mu Y, Xiao F, Lin SH, Shi M. Radiotherapy alone or concurrent Chemoradiation for esophageal squamous cell carcinoma in elderly patients. J Cancer. 2017;8(16):3242-50.

23. Guo JH, Chen MQ, Chen C, Lu HJ, Xu BH. Efficacy and toxicity of nimotuzumab combined with radiotherapy in elderly patients with esophageal squamous cell carcinoma. Mol Clinical Oncol. 2015;3(5):1135-8.

24. Ohba A, Kato K, Ito Y, Katada C, Ishiyama H, Yamamoto S, Ura T, Kodaira T, Kudo S, Tamaki Y. Chemoradiation therapy with docetaxel in elderly patients with stage I//II esophageal cancer: a phase 2 trial. Adv Radiat Oncol. 2016;1 (4):230-6.

25. Ishida K, lizuka T, Ando N, Ide H. Phase II study of chemoradiotherapy for advanced squamous cell carcinoma of the thoracic esophagus: nine Japanese institutions trial. Jpn J Clin Oncol. 1996;26(5):310-5.

26. Sakai K, Inakoshi H, Sueyama H, Oda J, Ito T, Tsuchida E, Sugita T, Matsumoto Y, Saito M, Saito A. Concurrent radiotherapy and chemotherapy with protracted 
continuous infusion of 5 -fluorouracil in inoperable esophageal squamous cell carcinoma. Int J Radiat Oncol Biol Phys. 1995;31(4):921-7.

27. Ohtsu A, Boku N, Muro K, Chin K, Muto M, Yoshida S, Satake M, Ishikura S, Ogino T, Miyata $Y$, et al. Definitive chemoradiotherapy for T4 and/or M1 lymph node squamous cell carcinoma of the esophagus. J Clin Oncol. 1999; 17(9):2915-21.

28. Nishimura Y, Suzuki M, Nakamatsu K, Kanamori S, Yagyu Y, Shigeoka H. Prospective trial of concurrent chemoradiotherapy with protracted infusion of 5-fluorouracil and cisplatin for T4 esophageal cancer with or without fistula. Int J Radiat Oncol Biol Phys. 2002;53(1):134-9.

29. Mariette C, Piessen G, Briez N, Triboulet JP. The number of metastatic lymph nodes and the ratio between metastatic and examined lymph nodes are independent prognostic factors in esophageal cancer regardless of neoadjuvant chemoradiation or lymphadenectomy extent. Ann Surg. 2008; 247(2):365-71:

30. Ren Y, Ye J, Xiong W, Zuo J, He Y, Tan M, Yuan Y. Adjuvant radiotherapy for positive lymph nodes of oesophageal squamous cell carcinoma: can it earn promising benefits at long-term follow-up? Cancer Radiother. 2018;22(2):140-7.

31. Han J, Zhu W, Yu C, Zhou X, Li T, Zhang X. Clinical study of concurrent chemoradiotherapy or radiotherapy alone for esophageal cancer patients with positive lymph node metastasis. Tumori. 2012;98(1):60-5.

32. Thomas William Rice DK, Eugene H, Blackstone HI, Patil DT, Bass AJ, Erasmus JJ, Gerdes H, Hofstetter WL. Esophagus and Esophagogastric Junction. In: AJCC CANCER STAGING MANUAL 8th. 1st ed: AMERICAN JOINTCOMMITTEEON CANCER Executive Office. Switzerland: Springer International Publishing AG; 2017. p. 185-202.

33. $X u H Y$, Wu SX, Luo HS, Chen CY, Lin LX, Huang HC. Analysis of definitive chemo-radiotherapy for esophageal cancer with supra-clavicular node metastasis based on CT in a single institutional retrospective study: a propensity score matching analysis. Radiat Oncol. 2018;13(1):200.

34. Chen YH, Lu HI, Lo CM, Wang YM, Chou SY, Huang CH, Shih LH, Chen SW, Li $\mathrm{SH}$. The clinical impact of supraclavicular lymph node metastasis in patients with locally advanced esophageal squamous cell carcinoma receiving curative concurrent chemoradiotherapy. PLoS One. 2018;13(6):e0198800.

35. Chen M, Li X, Chen Y, Liu P, Chen Z, Shen M, Liu X, Lin Y, Yang R, Ni W, et al. Proposed revision of the 8th edition AJCC clinical staging system for esophageal squamous cell cancer treated with definitive chemo-IMRT based on CT imaging. Radiat Oncol. 2019;14(1).

36. Piccirillo JF, Tierney RM, Costas I, Grove L, Spitznagel EL Jr. Prognostic importance of comorbidity in a hospital-based cancer registry. Jama. 2004 291(20):2441-7.

37. Barone BB, Yeh HC, Snyder CF, Peairs KS, Stein KB, Derr RL, Wolff AC, Brancati FL. Long-term all-cause mortality in cancer patients with preexisting diabetes mellitus: a systematic review and meta-analysis. Jama. 2008;300(23):2754-64.

38. Faiz Z, van Putten M, Verhoeven RHA, van Sandick JW, Nieuwenhuijzen GAP, van der Sangen MJC, Lemmens V, BPL W, JTM P. Impact of Age and Comorbidity on Choice and Outcome of Two Different Treatment Options for Patients with Potentially Curable Esophageal Cancer. Ann Surg Oncol. 2019; 26(4):986-95.

39. He L-R, Qiao W, Liao Z-X, Komaki R, Ho L, Hofstetter WL, Lin SH. Impact of comorbidities and use of common medications on cancer and non-cancer specific survival in esophageal carcinoma. BMC Cancer. 2015;15(1):1-10.

40. Hurria A, Gupta S, Zauderer M, Zuckerman EL, Cohen HJ, Muss H, Rodin M, Panageas KS, Holland JC, Saltz L, et al. Developing a cancer-specific geriatric assessment: a feasibility study. Cancer. 2005;104(9):1998-2005.

\section{Publisher's Note}

Springer Nature remains neutral with regard to jurisdictional claims in published maps and institutional affiliations.

Ready to submit your research? Choose BMC and benefit from:

- fast, convenient online submission

- thorough peer review by experienced researchers in your field

- rapid publication on acceptance

- support for research data, including large and complex data types

- gold Open Access which fosters wider collaboration and increased citations

- maximum visibility for your research: over $100 \mathrm{M}$ website views per year

At BMC, research is always in progress.

Learn more biomedcentral.com/submissions 